\title{
Analysis and Discussion on the Hierarchical Teaching of University Computer Public Course
}

\author{
LIU Enqi \\ School of information science and engineering \\ Northeastern University, \\ Shenyang Liaoning China 110000
}

\begin{abstract}
With the increasing status of computers in human society, how to train more innovative talents in line with new forms and computational thinking has become one of the new tasks of higher education in the country. The computer is an elective course for basic courses for non-computer majors, the main purpose is to popularize computer education, so that more students can master the modern computer tools, however, in the specific teaching process, colleges and universities have encountered some practical problems. In the analysis of the current teaching situation, combined with the actual teaching experience, this paper puts forward some reform ideas.
\end{abstract}

Keywords-Elective Course; Stratification; Computational Thinking; Teaching Methods; MOOC

\section{INTRODUCTION}

With the high speed growth of china' development. China's demand for education is getting higher and higher. One of the goals of our higher education training is to cultivate the talents with enterprising spirit and innovative ability, just as a proverb goes, "Knowledge is no burden." So how to make many non-computer major students can not only master the basic knowledge of computer or operate the computers skillfully, but also be able to use the computational thinking way to solve the problems they meet, has become a new aim in basic computer education in colleges. Associations of Fundamental Computing Education in Chinese Universities and Research Organization have made a comprehensive summary and a systematic study on domestic computer basic education, and have put forward some guarding suggestions. However, due to many factors such as the regional source, faculty, and laboratory construction and so on, there are still many differences in the establishment of computer public course and specific training programs.

\section{CURRENT SITUATION AND EXISTING PROBLEMS.}

Due to the differences in the hardware and software of various colleges and universities in China, the main problems in the computer science class are shown in the following aspects:

\section{A. Uneven student level}

With the popularization of computer education in primary and secondary schools in our country, quite a few students have been exposed to systematic computer knowledge in advance, however, there are still partial students who live in remote areas or come from the poor family have never contacted the computers, which lead to uneven student level. At present, the levels of students when they entered the colleges and universities form such a format, Figure 1:

Research shows that even the students on the middle level differ in their knowledge of the computer because of some other factors. For example, some students studied programming, some students studied Flash, and others just studied Microsoft Office or several basic operating software, and owing to the rapid update of software. Even the internal workings of the same name can be very different and so on. In this way, it is a big problem for the teachers to teach under the same syllabus, if it's easy, the students don't like it, on the contrary, the students cannot understand it.

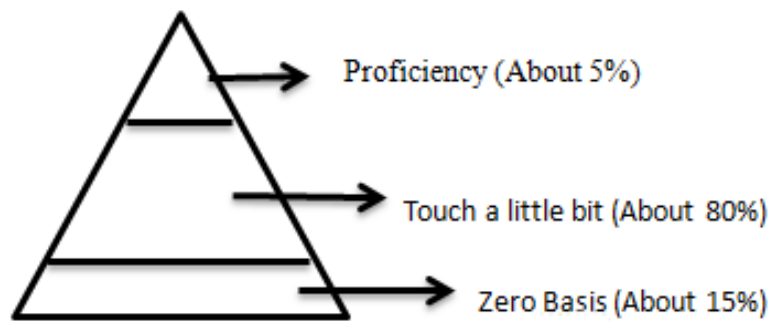

Fig. 1. The Diagram of differences on computer levels

\section{B. The lag of teaching content}

Computer public course in most colleges and universities are taught in two terms, [1] the content on first semester involves the computer basic knowledge. For example, the development of computer, the introduction of hardware and software, the operation of window system, Microsoft Office (Word, Excel, PowerPoint) and the foundation of network. Here's not going to talk about the overlap with primary and secondary schools, just in terms of the hardware, the computer's hardware is updated very quickly according to Moore's law. However, the speed of teaching materials cannot be achieved, so there is a phenomenon that teachers cannot teach completely in accordance with the textbook, and students also find that they cannot find new knowledge in their text books. What's more, most students still don't know how to buy a computer and how to analyze some of the parameters and hardware of the computer, even though they have learned the knowledge of the book, which is a typical theory that is out 
of practice, gradually they lose understanding of what they are learning. In addition, some students want to know more about the principles, maintenance and safety of some computer systems, but they are not reflected in the textbooks. In the second semester, most schools offer a program design course, such as $\mathrm{C}$, VB, etc...Although programming is a computer course, this knowledge is not interesting for most non computer students. In many years of teaching, many students have asked, "why let us non computer students learn programming, we have our own professional courses, if we all master programming, won't the computer professional students be unemployed?” Therefore, this course' effect on non computer students is not very obvious. We should combine programming with their course more and more closely. If we can do this, during the learning process, students could not only learn how to do programming better but also can enhance their own expertise to achieve efficient absorption.

\section{The Inflexible forms of teaching}

At present, in the process of the computer public course, the teacher is generally used to talking about the theory. For example, demonstrate the size of a document font, paragraph, type setting and other basic operations. However, we need to recognize that this is an era of information, on the Internet; we can already find a lot of learning resources, including video demonstration. And some colleges have good laboratories, which can be taught in this section. And we should also try our best to improve the teaching environment of the big classroom. After all, it's a hand-on operation, thus we should create a better environment for students to learn computer. To make students better understand the courses taught by teachers.

\section{The single mode of examination}

At present, the emphasis of College Computer Foundation Course in most colleges and universities is to cultivate students' proficiency in the use of computer ability, however, at the end of the final exam, the paper-based test paper was adopted, how to type setting in Word and how to use calculation formula in Excel, are actually asked the students to write test steps. Just imagine that can this assessment form truly reflect the actual level of the students? Besides, computer programming language, some colleges and universities have used the electronic examination paper for the test, but filling the blanks instead of programming problems. It`s certainly convenient for teachers to check papers, but is it beneficial for our student? Is it consistent with the original intention of training computational thinking? With the emergence of this phenomenon, our teachers have to be vigilant. Therefore we should change the test way, and use more test on computers to test students

\section{SOME REFORMS TO SOLVE THE PROBLEMS}

In view of the above problems, the general idea of teaching reform is as follows:

\section{A. Hierarchical and differentiated teaching}

\section{a) Hierarchy of students}

Taking into account that the levels of the students entering the school are uneven, so that it s unable to teach them in the same class. [2]When students enter the school, we can arrange a computer level test for them. According to the students' basic knowledge of computer, they will be divided into several classes. It is necessary to note that the best situation is to disrupt the original class divided by their majors, and to rearrange it to their level. This way that is certainly just for computer public courses requires school policy support, however, it`s difficult to operate. A more feasible way is to classify the students into different levels in a teacher's own class, but there is a premise that we cannot use the same syllabus.

\section{b) Hierarchy of students' interests}

Students can choose their own learning content independently according to their hobbies, combining their professional characteristics and following learning needs. For example, the students of journalism can focus on learning the news acquisition and editing, the students of architecture can focus on studying graphics editing and production. In addition, students who are interested in webpage making can learn more about software applications such as Dreamweaver, FrontPages and so on. We can even turn a computer into an optional course in a required course, each teacher will be responsible for one section, such as graphics editing and production or webpage making and so on. Then students can be selective. In this way, this kind of teaching method can improve students' interest in study, make students transformation from learning extensively to learning consummate, reduce the workload of teachers, improve the practical ability of future employment.

\section{B. Diversification of teaching methods [3]}

This is a period full of networking, digitalization, all kinds of communication software, and the great richness of hardware, for example WeChat. Teachers can use networked teaching, which can not only reduce the pressure of school building construction, but also keep in contact with students online. At the same time, we should develop the search of MOOC, micro class, etc. Knowledge points can be put into different media forms, and these resources can be kept for a long time and play a continuous learning role. In addition, some chapters and knowledge points do not need to be put on the theory class. Teachers can make use of synchronous presentation in the computer room directly, so that students can clearly see the steps and skills of operation on their screens so that students can absorb it better. You know, our enrollment is increasing. Many times, 1 teacher will face more than 100 people. The effect on teaching in a big classroom is not deal.

\section{The revolution of the test}

a) The form of the exam

Since most schools basically set up two courses, one is computer basis, the other is computer programming. It is suggested that we should make full use of the advantages of 
computer network and gradually transit from paper test to electronic test. Only in this way can we find out a student's ability to operate the computer and the actual level of debugging and programming. To achieve a fair and fair test and the purpose of selecting talents.

\section{b) The segmentation of exam content}

On the premise of the electronic examination, the paper should be automatically formed from a mass question bank, according to the students' majors. In this way, we can follow the aim of student-differed and interest-differed. It not only investigates the basic knowledge of the computer, but also adds different emphasis.

\section{c) The time of exam}

In the past, students' exams were carried out at the end of the semester. If we can make full use of the characteristics of the Internet, students can take the exams according to their own learning contents and abilities. To ensure the fairness, we can set the exam times and the proportion of each exam, the more times they are, the higher discounted the test scores will be, so that students will not be able to look down on the exam. And they will learn about the focus of the exam and they also will try their best to get the best course as soon as possible

\section{d) The assessment of grade [4]}

Just remember that, the process is more important than the result. The ultimate aim of our teaching is to make the students master more computer operations and cultivate consciousness of thinking. We can add the unit evaluation and stage evaluation of the daily practical operation, combined with the actual performance in class. And then reckon the above factions in the final grade. At the meanwhile, we should guarantee the transparency of the examination, make clear the details of the score so that students can know why he or she get this score. There should be a link to query their score. The teachers were not impressed by all their students, which caused a great deal of uncertainty. I think that if the government can make a policy which can let students query their scores the fairness of achievement will also be guaranteed.

\section{The reform of teaching materials}

At present, most content of computer teaching materials include binary, computer development, the basic concept of hardware and three pieces of office software. It's suggested that some practical content should be added appropriately, such as Installation and maintenance of computer operating system, how to ensure the safety of the Internet, how to use computers properly within the scope of the law etc.

\section{E. Encourage innovation}

First, we need to clear their own object is acollage student is not high school students is not primary school students, they have their own ideas, and we not only to teach the basis of their existing concept, simple operating system, the basic programming method, we have to intriduce them to the application of computer in the future life, the innovation direction of the computer, we want to encourage them to do their own scientific and technological innovation, every great man is starting from scratch, we want to encourage students to innovation thinking, let them can create their own through the efforts of your team. Small to a simple App, big to an operating system. This spirit of innovation is also a necessary spiritual accomplishment.

\section{CONCLUSION}

It's where technology plays a leading role today. Computer public course teaching is directly related to the quality of the education, the direct expression of a university's comprehensive ability level. The teaching of computer public course is directly related to the quality of education as well as the level of the comprehensive ability of a university. Hierarchical teaching, people-oriented, in accordance with students aptitude, and give full play to the initiative of students, so that the class teaching is no longer the situation that teachers impart signally and the students learn passively. This is the direction of current computer public course reform. Although the conditions of each school are so different that it will be difficult to implement them, we do hope these suggestions will be beneficial to the computer public course in colleges and universities.

\section{REFERENCES}

[1] Hou Jiali, Tang Hong: Journal of Dongguan University of Technology, Vol. 24 (2013) No.5, pp.102-107

[2] Qi Jin, Sun Yan, Wang Dongmei: Modern Business Trade Industry, Vol. 30 (2011) No.23, pp.237-238

[3] Zhang Fengyun, Li Xiangqun: Computer Knowledge and Technology, Vol.16 (2009) NO.5, pp.7187-7188.

[4] Zhang Yan, Jiang Wei, Guan Hongjie: Computer Education, Vol 8(2010) No.16, pp.14-16. 